\title{
SINAES: DO DOCUMENTO ORIGINAL À LEGISLAÇÃO
}

\section{SINAES: of the Original Document to the Legislation}

\author{
José Carlos Rothen ${ }^{1}$
}

Almiro Schulz ${ }^{2}$

\section{Resumo}

Inicialmente, analisa-se a distinção entre a função da formação e de controle da avaliação; um breve histórico da avaliação da Educação Superior no Brasil; o processo de elaboração e da implantação legal da nova Proposta; e, no último momento, que é a maior parte do trabalho, discutem-se as principais diferenças entre a Proposta e a Legislação.

Palavras-chave: SINAES; Proposta; Legislação.

\section{Abstract}

Initially it is analyzed distinction enters the function of the formation and control of the evaluation; a historical briefing of the evaluation of the Superior Education in Brazil; the process of elaboration and the legal implantation of new the proposal; e, at the last moment, that is most of the work, argues the main differences between the Proposal and the legislation.

Keywords: Avaliation; Educational politic; Superior education.

1 Professor Doutor, Centro Universitário do Triângulo, Curso de Mestrado em Educação. E-mail: jcr3219@yahoo.com.br

2 Professor Doutor, Centro Universitário do Triângulo, Curso de Mestrado em Educação. E-mail: almiroschulz@yahoo.com.br 
A avaliação da Educação Superior é uma realidade no contexto educacional brasileiro. Apesar da implantação das propostas de avaliação se iniciarem na década de 1980, apenas com a realização do Exame Nacional de Cursos (Provão), na segunda metade da década de 1990, o problema da avaliação atinge as Instituições de Educação Superior (IES) e os seus resultados repercutem na sociedade. Contudo, ainda não se tem um consenso sobre as questões: para quê, o quê e como avaliar?

No início do governo Lula, é instalada a Comissão Especial de Avaliação da Educação Superior (CEA) para elaborar uma nova Proposta de Avaliação. No início de 2004, é promulgada a Lei 10.861, que implanta o Sistema Nacional de Avaliação da Educação Superior (SINAES).

A apresentação da Lei, no site do MEC, é precedida do documento produzido pela CEA, dando a entender que a Lei é decorrência direta da Proposta da CEA. Na $27^{a}$ Reunião Anual da ANPED, nas discussões sobre o novo sistema, alguns pesquisadores apontavam que existiriam diferenças fundamentais entre a Proposta da CEA e a Legislação. Com base nessa hipótese, iniciamos um trabalho de investigação comparando o conteúdo da Proposta com o da atual Legislação. Como resultado, levantamos a hipótese de que existem diferenças fundamentais entre elas e que essas são decorrentes da concepção adotada pelos autores da função da avaliação, isto é, a CEA entende que a função predominante da avaliação é a formativa, enquanto que o legislador, que é predominante a de controle.

Inicialmente, apresentaremos a distinção entre a função da formação e de controle da avaliação; um breve histórico da avaliação da Educação Superior no Brasil; o processo de elaboração e da implantação legal da nova Proposta; e, no último momento, que é a maior parte deste trabalho, discutiremos as principais diferenças entre a Proposta e a Legislação.

\section{Formação e Controle}

O debate sobre o sistema de avaliação a ser adotado tem como pano de fundo a polêmica sobre a função da avaliação. $O$ antagonismo entre as categorias formação e controle (regulação) é representativa desse debate. Ambas podem ser compreendidas sob várias perspectivas, apesar de que a formação tem sido, mormente, objeto da filosofia e da pedagogia, ao passo que o controle, da sociologia e da psicologia social.

A palavra formação remete-nos à idéia de "forma" ou de "dar forma". No âmbito da educação, pode-se dimensionar a tríade: saber, fazer e ser. O saber como informação, transmissão e desenvolvimento do conhecimento acumulado de geração a geração, bem como a descoberta de novos conheci- 
mentos. Na linguagem das competências, pode ser dito como competência cognitiva.

O fazer - como instrumentalização para a realização, a capacidade e o desenvolvimento técnico e de seu uso na construção e transformação dos recursos da natureza, a invenção, aperfeiçoamento e descoberta de novos meios tecnológicos -corresponde à competência técnica.

A formação do ser significa a humanização do homem, por meio do desenvolvimento, do seu potencial para as virtudes e a prática dos valores, ou seja, a dinamização da dimensão ética e política.

A formação não é um dado, mas uma construção, um processo, não necessariamente contínuo, linear. Depende da cosmovisão adotada. Destacamos que ela implica em pedagogia, metodologia, que, no campo da educação, para os gregos, era a Paidéia. Gislene Santos (2001, p. 152-3) destaca alguns aspectos importantes da Paidéia grega. Ressaltamos duas: 1) a formação não se reduzia a uma soma de técnicas, centradas numa preocupação com a formação individual e independente; visava à formação integral do homem no interior da coletividade como cidadão; 2) é a busca da excelência do homem por meio da educação, que não se desvinculava das virtudes (aréte) e dos valores. Cabanas (1998, p. 393) afirma que "pues los valores constituyen los fines de la educación y, com el modo del educar aludido, se compromete el sentido y la eficacia de la propia acción educativa".

Na LDB, no Art. $1^{\circ}$, apresenta-se a crença na possibilidade de formação do homem para a civilidade no espaço e tempo da escola; no Art. $2^{\circ}$, destacamos dois princípios fundamentais na formação: a liberdade e os ideais da solidariedade, enquanto, para o processo de formação, a ênfase é dada ao exercício da cidadania e à qualificação para o trabalho. É possível tecer uma crítica sobre a operacionalização do ideal da formação voltada para os valores e a ética, pois, ao tratar sobre a quem cabe a tarefa da formação, a LDB a restringe ao exercício da docência, isentando a sociedade, bem como o próprio sistema de educação dessa função ou papel. É importante lembrar que a formação se dá por meio de uma complexidade de meios e formas, entre eles, também, a educação escolar.

Os textos objetos desta pesquisa fazem uso dos termos regulação e controle cuja distinção entre eles nem sempre está clara. Passamos a usar a categoria controle, que pode ser vista, no mínimo, sob dois níveis básicos: do ponto de vista, do autocontrole, individual, interno, e do ponto de vista do controle coletivo, social e externo.

Tratando-se do sistema de avaliação como controle de ações e desempenho institucional, organizacional, que envolve o processo de gestão e administrativo, iremos nos ater a algumas considerações mais do ponto de vista administrativo. Nesse sentido, iremos nos valer do texto de Robbins e 
Coulter, que definem o controle como "processo de monitorar as atividades de forma a assegurar que elas estejam sendo realizadas conforme o planejamento e corrigir quaisquer desvios significativos" (1998, p. 414).

O controle, nessa perspectiva, remete-se a um sistema que tem como parâmetro a eficiência, envolvendo custo e benefício; eficácia, envolvendo metas e resultados quantitativos. Porém, tratando-se de organizações educacionais, não pode ficar de fora a concepção de efetividade, que é o controle voltado para a qualidade, a excelência.

Qualquer controle vale-se de procedimentos, mecanismos, que podem ser ocultos, diluídos, ou expressos de forma objetiva. Robbins e Coulter (1998, p. 414-5) relacionam três sistemas de controle no campo administrativo: o controle "de mercado", que enfatiza os mecanismos, sobretudo externos, tais como a competição de preço e a participação de mercado, visando, o ranking. O sistema burocrático, com ênfase na autoridade, estabelecimento de regras, definição de funções, procedimentos e políticas administrativas. O controle por intermédio de um sistema de valores, crenças e tradição que constituem a cultura organizacional.

Outro aspecto sobre o qual se pode perguntar é se de fato o controle é significativo, importante num processo de gestão de um sistema qualquer? Tratando-se de um conjunto de ações em que são estabelecidos objetivos, metas a serem alcançadas, ou seja, no qual existe um planejamento, Robbins e Coulter (1998, p. 415) explicam que "o controle é importante porque representa o último elo na cadeia funcional das atividades da administração". É fundamental para que se tenha conhecimento se os objetivos, os planos são cumpridos e que ações empreender para o futuro.

Ainda há um outro ponto ao qual queremos nos referir, que é sobre o processo do controle. Mais uma vez usando as considerações de Robbins e Coulter, no campo da gestão e administração, são três os passos principais: "medir o desempenho real", que por sua vez nos remete a perguntar o que medir e como medir. "É mais importante para o processo de controle saber o que medimos do que como medimos" (1998, p. 416). Segundo, "comparar o desempenho real com um padrão", o que possibilita a verificação do grau de variação entre o desempenho real e o padrão estabelecido. A questão que se coloca é qual o padrão em que desvios serão considerados aceitáveis ou que ultrapassam e merecem a atenção para o controle? Terceiro, "empreender ações administrativas para corrigir desvios ou padrões inadequados". Nesse passo, Robbins e Coulter lembram que, ao se decidir corrigir o desempenho real, isso implica uma ação corretiva que chamam de básica ou imediata. 
A ação corretiva imediata corrige os problemas imediatamente e faz com que o desempenho volte ao esperado. A ação corretiva básica pergunta por que e como o desempenho sofreu desvio, e aí então se empenha em corrigir a origem do desvio ( 1998, p. 418).

Com essas considerações preliminares como ponto de referência, estaremos analisando como a formação e o controle perpassam a Proposta do SINAES, bem como são postas na legislação da avaliação.

\section{Antecedentes da avaliação institucional no Brasil}

As experiências de avaliação metódica do Sistema Universitário se iniciaram no Brasil, na década de 1980, com o "Programa de Avaliação da Reforma Universitária" (PARU, 1983-6) e com as experiências de universidades como da UnB e da Unicamp (BELLONI, 2000; DIAS SOBRINHO, p. 62-85). Essas experiências inspiraram o "Programa de Avaliação Institucional das Universidades Brasileiras" (PAIUB), o qual tentava conciliar avaliação interna com externa, tendo como princípio que o papel da avaliação é prioritariamente emancipatório (AFONSO, 2000, p. 123-5). De acordo com a Proposta do PAIUB,

A avaliação de desempenho da Universidade Brasileira é uma forma de rever e aperfeiçoar a projeto acadêmico e sócio-político da instituição, promovendo a permanente melhoria da qualidade e pertinência das atividades desenvolvidas. A utilização eficiente, ética e relevante dos recursos humanos e materiais da universidade traduzida em compromissos científicos e sociais, assegura a qualidade e a importância dos seus produtos e a sua legitimação junto à sociedade (PAIUB, 1993).

Os pontos fundamentais desses objetivos seriam: a idéia de que a universidade deveria ter um projeto, a visão de que a qualidade deveria ser promovida, e de que as ações da universidade teriam de ser baseadas na ética e no compromisso social. No PAIUB, tinha-se como pressuposto que a avaliação das IES decorria das seguintes exigências da universidade contemporânea:

a) um processo contínuo de aperfeiçoamento do desempenho acadêmico;

b) uma ferramenta para o planejamento e gestão universitária;

c) um processo sistemático de prestação de contas à sociedade (PAIUB, 1993).

A concepção de que a Universidade prestaria contas à sociedade não implica, na Proposta do PAIUB, que o processo de avaliação inicie-se fora da IES. Ao contrário, inicia-se dentro dos seus muros, respeita a autonomia uni- 
versitária. Apesar de o PAIUB ser uma política de Estado, a adesão das Instituições era voluntária, isto é, foram estimuladas a elaborar projetos de autoavaliação

No documento básico do PAIUB encontra-se a idéia de que toda avaliação é institucional, isto é, que a avaliação é indissociável de suas várias dimensões. Contudo é proposto que a avaliação inicie-se pelo ensino de graduação, com a justificativa de que para que a tarefa fosse realizável, seria necessário reduzir o que seria avaliado e pelo impacto que o ensino de graduação promove na sociedade.

O PAIUB não foi formalmente extinto, ele foi relegado a um segundo plano pelo MEC no início do octênio governamental anterior, até ser extinto por inanição, quando da adoção do Provão (1997). Os novos procedimentos de avaliação das IES foram implantados gradualmente por atos legislativos, não sendo publicado documento algum explicitando uma Proposta de Avaliação.

No final de 1995, foi editada a Medida Provisória (MP) 1.159 de 26/ 10/1995, que foi transformada na Lei 9.131, de 24/11/1995. Por esse ato legislativo, é alterada a LDB de 1961 em dois pontos: extingue o Conselho Federal de Educação e cria o Conselho Nacional de Educação, e prevê ainda ser de competência do MEC a avaliação periódica dos cursos de graduação. O único instrumento de avaliação previsto nessa Lei foi o Provão. Apenas em 10/10/ 1996 foi expedido o Decreto 2.021 regulamentando os procedimentos da avaliação. O Art. $1^{\circ}$ do Decreto determinava:

O processo de avaliação dos cursos e instituições de ensino superior compreenderá os seguintes procedimentos:

I. análise dos principais indicadores de desempenho global do sistema nacional de ensino superior, por região e unidade da federação, segundo as áreas do conhecimento e o tipo ou a natureza das instituições de ensino; II. avaliação do desempenho individual das instituições de ensino superior, compreendendo todas as modalidades de ensino, pesquisa e extensão; III. avaliação do ensino de graduação, por curso, por meio da análise das condições de oferta pelas diferentes instituições de ensino e pela análise dos resultados do Exame Nacional de Cursos;

IV. avaliação dos programas de mestrado e doutorado, por área do conhecimento.

O processo de avaliação da Pós-Graduação (mestrado e doutorado) antecede ao Decreto e é de responsabilidade da CAPES; o Decreto apenas manteve o que já estava consolidado. A avaliação do desempenho global ocorreu a partir do "censo anual do ensino superior".

O desempenho individual das instituições foi o último procedimento implantado, e foi realizado com o objetivo de fornecer subsídios para o 
(re)credenciamento de universidades e centros universitários. A avaliação do ensino de graduação acontecia no momento do reconhecimento dos cursos de graduação.

Entendemos que a redução da avaliação à autorização do funcionamento das instituições foi fruto da concepção de Estado Avaliador adotado pelo MEC e pela sua estratégia de implantar um sistema de avaliação sem discutir o modelo "ideal" de universidade (AFONSO, 2000, p. 49-51). No discurso oficial, o Provão era apresentado como um dos instrumentos na avaliação das IES. Contudo, foi o instrumento quase exclusivo, tanto que o resultado dessa avaliação era amplamente divulgado, o que não sucedia com o resultado das outras avaliações. Essa valorização é coerente com a concepção de que apenas compete ao Estado avaliar as Instituições e estimular a concorrência entre elas, no caso pela divulgação de rankings, o que permitiria ao "mercado consumidor" de educação escolher as "melhores" Instituições.

\section{A elaboração da nova Proposta}

A elaboração e implantação da Proposta do SINAES é marcada por embate político nos bastidores do governo Lula. Dividimos em três momentos esse processo: a fase de elaboração, a promulgação da legislação e a instalação da CONAES.

No início do governo Lula foi constituída a Comissão Especial de Avaliação da Educação Superior (CEA), designada mediante Portaria da Secretária da Educação Superior (SESu), com prazo de 120 dias para elaborar propostas e subsídios para alteração do sistema da Avaliação da Educação Superior. A comissão foi composta por representantes da SESu, do Instituto Nacional de Estudos e Pesquisas Educacionais Anísio Teixeira (INEP) e de 11 especialistas ligados às universidades públicas e privadas.

No período em que a CEA desenvolveu os seus trabalhos, a grande questão apresentada ao público referia-se à validade do Provão e se esse deveria ter continuidade. São representativas desse debate as posições de Cristóvam Buarque, na época ministro da educação, e a de Otaviano Helene, então presidente do INEP.

Buarque, no texto "Avaliando a Avaliação", defendeu a necessidade da avaliação da Educação Superior e que o Provão teria os seus méritos apesar de ser instrumento parcial de avaliação; considerava que a Proposta de avaliação institucional implantada na UnB, na sua gestão como reitor dessa Instituição, foi completada pelo Ministro Paulo Renato, quando este implantou o Provão. 
Helene publicou, no site do INEP, o artigo "O INEP e as avaliações", no qual fez o balanço das atividades do Instituto na coordenação da avaliação dos sistemas educacionais. $\mathrm{O}$ artigo de Helene, no geral, tinha um tom sereno e elogioso às avaliações desenvolvidas pelo Instituto. Porém, ao tratar sobre o Provão, o tom mudou; após uma rápida descrição do instrumento, ele apontou que o Provão foi severamente criticado por setores da sociedade, principalmente, pela forma como seus resultados eram divulgados.

Nesse contexto de embate político, foi editada a Portaria MEC 110, que dispunha sobre a implantação do Sistema Nacional de Certificação e Formação Continuada de Professores da Educação Básica. Na questão da avaliação, a Portaria vinculou a certificação dos professores da educação básica aos resultados obtidos no Provão. É interessante observar que a Portaria foi publicada no diário oficial de 10/6/2003, dois dias após a realização do Provão, dois meses antes da CEA apresentar o resultado de seus trabalhos, e cinco dias após a divulgação no site do INEP do texto do seu presidente questionando a validade do Provão. Esse contexto no qual foi editada a Portaria permite-nos levantar a hipótese de que a sua edição objetivava consolidar definitivamente a realização do Provão.

Em 15/12/2003, ainda na gestão de Buarque, foi editada a MP 147, instituindo o "Sistema Nacional de Avaliação e Progresso do Ensino Superior". A MP fortalecia o MEC e o INEP como agentes principais da avaliação das IES. Em linhas gerais, ela foi mal estruturada - por exemplo, era dúbia ao definir de quem seria a atribuição de divulgar os resultados ${ }^{3}$ - e omissa em relação a aspectos importantes - por exemplo, de quem seria competência de avaliar a pós-graduação.

No dia 27/1/2004, com a reforma ministerial realizada pelo presidente Lula, assumiu Tarso Genro o Ministério da Educação. Após a troca do ministro, o deputado Dr. Evilásio (PSB/SP), relator do projeto de Lei de Conversão da MP, na Câmara dos Deputados, apresentou o projeto que alterou o conteúdo da MP 147. Finalmente, a Lei de Conversão foi aprovada pelo Congresso Nacional transformando-se na Lei 10.861 e em 14/4/2004 ela foi sancionada pelo Presidente da República.

A Lei 10.861 foi regulamentada pela Portaria MEC 2.051 de 9/7/2004. Em agosto de 2004, a Comissão Nacional de Avaliação da Educação Superior (CONAES), instituída pela Lei 10.861, publicou os documentos "Diretrizes para a Avaliação das Instituições de Educação Superior" e "Roteiro para a Avaliação Interna". Como discutiremos adiante, os documentos da CONAES retomam o enfoque da avaliação formativa presente na Proposta da CEA, que tinha sido substituído pelo enfoque da avaliação como controle na Lei.

3 Ver o inciso VII do Art. 5 e o Art. 11. 


\section{As Diferenças Conceituais e Operacionais entre a Proposta e a Legislação}

A diferença fundamental da Proposta da CEA e da legislação que instaurou o SINAES é o entendimento da função da avaliação. Na Proposta, defende-se, explicitamente, que a função predominante é a formação das IES, enquanto, na legislação, os resultados da avaliação serão referencial "básico dos processos de regulação e supervisão da educação superior".

Ao apresentar os princípios e critérios que norteiam a organização da Proposta, a CEA inclui um item intitulado "Regulação e Controle", apontando que é necessária a função burocrática e legalista da regulação. Sugere que o controle deve ser articulado à avaliação educativa, isto é, que seja uma prática formativa e construtiva (CEA, 2004, p. 85-6). No final do documento, o problema da relação entre o controle e a avaliação é retomada. Nesse ponto, a CEA explicita: "concebe-se a avaliação como um processo que procede sem desdobramentos de natureza controladora ou de fiscalização" (CEA, 2004, p. 124). Desta forma, a função de controle e a de formação da avaliação ocorrem paralelas, uma não é conseqüência e nem determinada pela outra.

No $₫$ Único do Art. $2^{\circ}$, que prevê os aspectos que devem ser assegurados na avaliação da educação superior, é definido o vínculo da avaliação com a regulação. Nos termos da legislação:

Os resultados da avaliação referida no caput deste artigo constituirão referencial básico dos processos de regulação e supervisão da educação superior, neles compreendidos o credenciamento e a renovação de credenciamento de instituições de educação superior, a autorização, o reconhecimento e a renovação de reconhecimento de cursos de graduação.

Nessa discussão, encontra-se a diferença entre as concepções do papel do Estado em relação às IES. Na legislação, mantém-se a visão do Estado Avaliador presente no processo anterior de avaliação, isto é, compete ao Estado apenas avaliar e controlar as IES. Por sua vez, na Proposta, está implícita a idéia de que a Universidade é autônoma e que compete ao Estado intervir nos processos de avaliação, oferecendo apoio técnico às Instituições.

\section{CONAES}

A figura da Comissão Nacional de Avaliação da Educação Superior (CONAES) está presente tanto na Proposta como na Lei 10.861, de 14/04/2004. Na Proposta, a CONAES é o núcleo coordenador e executor do SINAES; na Lei 10.861, o seu papel é de coordenar e supervisionar as avaliações, sendo o INEP o órgão executor do processo de avaliação. 
Na comparação dos verbos utilizados na Proposta e na Lei 10.861 para definir as competências da CONAES, tornam-se evidentes as diferenças de atribuições. Na Proposta, identificamos a utilização de verbos que expressam ações diversificadas:

a) a execução da avaliação: institucionalizar, coordenar, avaliar, fazer, assegurar, dar estabilidade, instituir, receber, analisar e emitir parecer, informar, formular, estabelecer, divulgar, indicar, promover e organizar;

b) de apoio e estímulo: oferecer, facilitar, estimular.

Na Lei 10.861, apesar do caput do Art. $6^{\circ}$ manter a função de coordenação do SINAES pela CONAES, os verbos que denotam execução são substituídos por verbos que indicam a formulação de princípios:

- "institucionalizar" e "avaliar" por "propor";

- "fazer" por "apoiar";

- "dar estabilidade" por "assegurar";

- "instituir" por "estabelecer diretrizes"; e

- "promover a articulação" por "articular-se";

Ainda comparando a Proposta com a Lei 10.861, observa-se, primeiro, que as competências de execução da avaliação são transferidas da CONAES para MEC e ao INEP. A execução da avaliação e a divulgação do resultado, que seriam competência da CONAES, na Lei, são, respectivamente, competências do INEP e do MEC. Segundo, que são excluídas as competências relativas ao apoio técnico às instituições, de articulações entre os instrumentos de avaliação e de análise dos resultados globais. No $\mathbb{S}$ Único do Art. $3^{\circ}$, da Portaria 2.051, que regulamenta o SINAES, as competências relativas ao apoio técnico às instituições são novamente inseridas como facultativas à CONAES, isto é, a CONAES poderá ou não realizá-las.

A descaracterização das funções da CONAES é coerente com a visão de que é função do Estado apenas controlar as IES mediante avaliação. A ênfase à função de controle torna-se mais clara ainda na eliminação das competências de análise dos resultados globais, pois essa análise implicaria a formulação de ações de governo para o desenvolvimento dos sistemas de Educação Superior e das diversas áreas do conhecimento. 


\section{CONAES X INEP}

Na organização do sistema anterior de avaliação, o INEP tinha papel central. A Lei 1.568 de 14/2/1997, que transformou O INEP em autarquia, prevê, no Art. $1^{\circ}$, as finalidades do Instituto. Ressaltamos as relacionadas à avaliação:

VI - coordenar o processo de avaliação dos cursos de graduação, em conformidade com a legislação vigente;

VIII - promover a disseminação de informações sobre avaliação da educação básica e superior.

O Decreto 3.879 de 1/8/2001 que Aprova a Estrutura Regimental e o Quadro Demonstrativo dos Cargos em Comissão e das Funções Gratificadas do INEP, no seu Art. 10, define as atribuições da Diretoria de Estatística e Avaliação da Educação Superior. Destacamos a relacionada à avaliação

IV - propor, planejar, programar e coordenar ações voltadas para a avaliação dos cursos e instituições de ensino superior, articulando-se com os sistemas federal e estaduais de ensino.

No governo Lula, as atribuições dessa Diretoria do INEP foram reafirmadas pelo Decreto 4.633 de 21/4/2003. Do exposto, observa-se que, na legislação anterior, o INEP era o órgão responsável por coordenar, divulgar os resultados da avaliação. A CEA propôs que parte significativa das atribuições do INEP fosse transferida para a CONAES. Não está claro, na Proposta, se deveria ser montada uma estrutura paralela à do INEP para a realização da avaliação das IES ou se haveria a cooperação entre a CONAES e o INEP.

É importante ressaltar que a CEA (2004, p. 124) defende explicitamente a separação entre a avaliação, com a função de formar, e a de controle. Na seção intitulada "O SINAES e as funções regulatórias do poder público", após apontar a necessidade de o Estado aperfeiçoar a sua função de controle, a CEA defende que essa função deveria ser exercida pela SESu com assessoria técnica do INEP. Assim, as ações da CONAES estariam vinculadas à formação e as do INEP ao controle.

Na legislação anterior e na Proposta, não são diferenciados os papéis de coordenar e de realizar (executar) a avaliação, isto é, quem coordena realiza. A separação entre a coordenação e a execução da avaliação aparece na primeira redação da MP 147, que institui duas comissões: Comissão Nacional de Orientação da Avaliação (CONAV); e Comissão Nacional de Avaliação e Progresso do Ensino Superior (CONAPES). A primeira Comissão - composta por membros da comunidade acadêmica - estabeleceria as diretrizes gerais, e 
a segunda comissão - composta por representantes do MEC, INEP e CAPES realizaria a avaliação. A Lei 10.861, que não prevê as duas comissões criadas pela MP, mantém a distinção supracitada, sendo de competência da CONAES coordenar e do INEP executar.

Qual o significado da distinção entre coordenar e realizar? Por que a separação? Inicialmente pode se ter à impressão de que é uma separação equivalente entre as funções legislativa e a executiva. Em um segundo momento, levantamos a hipótese de que é uma tentativa de conciliar as duas visões concorrentes sobre a função da avaliação, presentes no governo. Dois indícios reforçam a hipótese: primeiro, na Lei 10.861 , no $₫ 1 .^{\circ}$ do Art. $1 .^{\circ}$, ao definir a finalidade do SINAES assume-se a visão formativa. Nos termos da legislação,

O SINAES tem por finalidades a melhoria da qualidade da educação superior, a orientação da expansão da sua oferta, o aumento permanente da sua eficácia institucional e efetividade acadêmica e social e, especialmente, a promoção do aprofundamento dos compromissos e responsabilidades sociais das instituições de educação superior, por meio da valorização de sua missão pública, da promoção dos valores democráticos, do respeito à diferença e à diversidade, da afirmação da autonomia e da identidade institucional.

Já no §. Único do Art. 2. ${ }^{\circ}$, que apresenta as características gerais do SINAES, tem-se a definição de que a avaliação terá função regulatória. Nos termos da legislação:

Os resultados da avaliação referida no caput deste artigo constituirão referencial básico dos processos de regulação e supervisão da educação superior, neles compreendidos o credenciamento e a renovação de credenciamento de instituições de educação superior, a autorização, o reconhecimento e a renovação de reconhecimento de cursos de graduação.

O segundo indício é o documento publicado pela CONAES intitulado "Diretrizes para a avaliação das Instituições de Educação Superior", no qual se busca retirar a ênfase da função regulatória da avaliação. Apesar de a CONAES conceder que o resultado da avaliação seja utilizado na função regulatória (p. 11), o documento em sua totalidade é construído nos moldes da Proposta da CEA, enfatizando a função formativa.

\section{Auto-avaliação Institucional}

A auto-avaliação das Instituições é prevista tanto na Proposta como na Lei 10.861. A semelhança termina na previsão da sua realização. Na Pro- 
posta, a auto-avaliação é a figura central da avaliação; pode-se declarar que ela é a avaliação das instituições (CEA, 2004, p. 94). No $₫ 2 .^{\circ}$ do Art. 3..$^{\circ}$ da Lei 10.861, que explicita as diversas dimensões institucionais que, obrigatoriamente, devem ser avaliadas, a auto-avaliação é reduzida a um dos diversos instrumentos de avaliação.

A diferença da ênfase dada à auto-avaliação também é decorrência concepção de avaliação adotada. Na CEA, partindo da idéia da avaliação formativa, o processo é centralizado nos trâmites internos das IES. Por sua vez, a visão de controle, presente na Lei 10.861, implica a centralização da avaliação nas agências do Estado.

A CONAES, no documento "Diretrizes para a avaliação das Instituições de Educação Superior", retoma a Proposta original de centralizar a avaliação das IES na auto-avaliação. Na introdução do capítulo 4 do documento "Diretrizes para a implementação do SINAES", está explícita a centralidade da auto-avaliação

Das considerações anteriores decorrem algumas diretrizes da Conaes para a avaliação das instituições: comparar o projeto da IES e a sua realidade institucional, ou seja, melhorar a qualidade acadêmica significa, no contexto de cada instituição, diminuir a distância entre ambos; construir uma proposta de auto-avaliação voltada para a globalidade da instituição, buscando dimensionar a relação entre o projeto institucional e sua prática, para reformulá-lo no planejamento e nas ações futuras da instituição; e elaborar uma metodologia que organize as atividades dos diferentes atores envolvidos no processo avaliativo, buscando a construção de um sistema integrado. Deste modo, ampliando as formas de compreensão sobre a instituição, visa a aperfeiçoar os diferentes (CONAES, 2004, p. 17).

\section{Instituição X cursos}

Na discussão de qual deve ser a articulação da avaliação das instituições com a dos cursos e qual delas deve ser priorizada, a diferença entre a Proposta e a Lei 10.861 é tênue, mas significativa. Na Proposta, a ênfase ocorre na avaliação das instituições, a de cursos é apenas um instrumento da avaliação (CEA, 2004, p. 125).

Na Lei 10.861, é determinado que, na avaliação, sejam considerados três dimensões da avaliação: das IES, dos cursos de graduação e do desempenho acadêmico de seus estudantes. Interpretamos que a ordem da apresentação das dimensões a serem avaliadas representa a hierarquização destas; estando, no topo, a avaliação das instituições e, na base, a avaliação do desempenho acadêmico de seus estudantes. Contudo, a avaliação de cursos pode 
ser autônoma em relação à institucional. No $\ 3^{\circ}$, do Art. $3^{\circ}$ da Lei 10.861, é previsto que, para cada uma das três dimensões (Instituição, Curso, Desempenho dos estudantes), será aplicado um conceito em uma escala de cinco níveis. No Art. 32 da Portaria MEC 2.051, é explicitado que as avaliações das Instituições e dos cursos têm conseqüência própria, isto é, prevê-se que o nível três é o indicativo de "mínimo aceitável" no "processos de autorização, reconhecimento e renovação de reconhecimento de cursos e de credenciamento e recredenciamento de instituições".

\section{Avaliação do produto}

Na Proposta e na Legislação do SINAES é determinada a realização de uma prova pelos estudantes. Na Proposta esta prova é nomeada de PAIDEIA (Processo de Avaliação Integrada do Desenvolvimento Educacional e da Inovação da Área) e, na legislação, de ENADE (Exame Nacional de Desempenho dos Estudantes). Nos dois casos, procura-se superar as limitações do Provão. O PAIDEIA e o ENADE têm as seguintes semelhanças:

a) realiza-se a prova por grupos amostrais;

b) avalia-se o conhecimento agregado, a prova é aplicada em pelo menos em dois estágios da realização do curso;

c) supera-se a avaliação de competência, habilidades e conteúdos exclusivamente profissionais

E, em linhas gerais, são as seguintes diferenças:

a) O PAIDEIA seria elaborado buscando valorizar a avaliação formativa, isto é, "sem a conotação mercadológica e competitiva, e sem dar margem ao estabelecimento de rankings" (CEA, 2004, p. 111). Por sua vez, o ENADE, apesar de buscar superar as limitações dos critérios de atribuição dos conceitos no Provão, mantém o objetivo, implícito de classificar os cursos, pois prevê a mesma escala de cinco níveis de conceitos a serem atribuídos a cada curso.

b) Na Proposta é implícito que a prova seria realizada por áreas, sendo elas: "a) Ciências Humanas, Sociais, Letras e Artes; b) Exatas; c) Tecnológicas; d) Biológicas e da Saúde" (CEA, 2004, p. 113). Ainda é proposto que será competência da CONAES decidir sobre a subdivisão das áreas. Por sua vez, na Lei 10.861, é adotado o mesmo critério estabelecido para o Provão, a prova será aplicada por cursos de graduação.

c) No PAIDEIA, propõe-se a aplicação de instrumento visando conhecer "as percepções (dos estudantes) sobre a evolução da formação, currí- 
culo, práticas pedagógicas, infra-estrutura, projetos de inovação, pontos positivos e carências da área avaliada e dos seus cursos" (p. 113). A legislação prevê a aplicação de instrumento para identificar o perfil dos estudantes com o objetivo de compreender os resultados alcançados.

d) No âmbito nacional, o PAIDEIA seria um instrumento para o conhecimento do desenvolvimento de cada área "para que isso fundamente e efetivamente induza políticas tendentes à superação de problemas e à elevação da qualidade do ensino de graduação" (CEA, 2004, p. 114). A Lei 10.861 é omissa em relação a essa orientação, isto é, não impede que esse tipo de análise seja feito, mas não a coloca como objetivo do ENADE.

\section{A divulgação dos resultados: estabelecimentos de ranking}

A CEA propõe que os resultados sejam divulgados pela CONAES de forma que não seja possível estabelecer ranking. A divulgação dos resultados seria efetuada mediante a emissão de um relatório apontando os pontos fracos e fortes da instituição. Na legislação, cada uma das dimensões da avaliação (Institucional, Curso e ENADE) recebe um conceito em uma escala de cinco níveis. Pelo que é previsto na legislação, é possível o estabelecimento de ranking para cada uma das dimensões.

\section{Ética}

Um dentre os aspectos pelos quais é possível perceber a diferença de focos entre a função da avaliação - formativa (Proposta) e controle (Lei) - é a diferença de ênfase dada à ética na Proposta e na Legislação. Abordaremos essas diferenças pontuando, primeiro, o aspecto quantitativo e, em seguida, o qualitativo.

O termo ética é mencionado de forma direta na Proposta 14 vezes, nas páginas: 82, 84, 85, 86, 87, 88, 90, 91 e 113, sendo que, em 9 referências, vem citado juntamente com política, como, por exemplo: "formação ética e política", "dimensão política e ética". De forma indireta, em que se pode fazer uma relação com a ética, constatam-se 6 referências, por intermédio do uso de termos e frases como: "juízo moral", "compromisso social", "cidadania”, "hábitos", "código de comportamento" e da denominação do instrumento como o PAIDEIA.

Na Lei 10.861, o termo ética não é citado nenhuma vez de forma direta. No sentido indireto, pela qual seria possível estabelecer uma relação, ocorre duas vezes: no Art. $1^{\circ}$, com referência a valores democráticos e no, Art. $5 .^{\circ}, \S 10$, aparece o termo excelência. 
Em relação aos aspectos qualitativos, a primeira observação que tencionamos fazer é que, mesmo que a referência à ética seja um destaque na Proposta, o seu uso é vago, generalista. Por exemplo: "Exigência ética dos processos educacionais", sem esclarecer, ou especificar, o que se entende; "imperativo ético da construção"... "Formação ética e política", como dito, usado várias vezes, sem, todavia, detalhar. Entretanto, no contexto do texto, é possível entender que, em parte, a ética está relacionada com avaliação democrática, participativa, pois explica: "a exigência ética própria dos processos educacionais conclama a todos [...] a se envolverem nas ações avaliativas" (CEA, 2004, p. 82). A idéia da responsabilidade aparece, pontuando, assim, a conduta no processo de avaliação. Pode-se ainda apreender que se entende por ética, no contexto da avaliação, a sua pluralidade, o respeito às diferenças institucionais, o espírito de solidariedade e de cooperação no decorrer da avaliação (CEA, 2004, p. 88).

O segundo aspecto que salientamos é que, na Proposta, a preocupação ética fica evidenciada pelas referências relacionadas com o processo formativo, com o educando, com a construção de uma estrutura organizacional e avaliativa e com uma gestão ética do processo. Em especial, destaca-se o instrumento para a avaliação, denominado o PAIDEIA, no qual está implícito o aspecto ético, pois, como já citado ao discutir a distinção entre formação e controle, Paideia significa um conjunto de procedimentos, não só técnicos, mas educativos, formativos, portanto, também éticos. Paidéia grega significava o processo educativo com uma relação estreita com aréte, formação das virtudes.

O terceiro aspecto que observamos é que as duas referências indiretas, que poderiam sinalizar um foco ético no texto da Lei, não são suficientes para que se possa concluir que essa questão esteja posta como uma preocupação.

\section{Considerações Finais}

As diferenças apresentadas neste texto entre a Proposta e a Legislação são conseqüências das concepções da função da avaliação adotadas em cada uma delas, respectivamente: a de formação e a de controle. Ainda, buscando explicar as possíveis causas das diferenças, entendemos que no governo Lula ainda não é consenso a função a que a avaliação deve atender.

Apesar das diferenças, compreendemos que o conteúdo da Proposta e da Legislação constituiu um avanço em relação aos procedimentos de avaliação anterior, pois se cria um sistema integrado de avaliação, em lugar de um amontoado de instrumentos. Nos dois casos, apesar da ênfase distinta, a ava- 
liação das Instituições, em sua totalidade, é priorizada corrigindo parte das distorções do sistema anterior.

$\mathrm{Na}$ avaliação, a formação e o controle não são necessariamente excludentes, isto é, não significa que um aspecto deva negar o outro. A delimitação da conciliação entre as duas funções está inserida na discussão sobre a autonomia universitária, sobre as exigências de diversificação das IES para que atendam as necessidades regionais e sobre o tipo de prestação de contas que deve ser oferecida à sociedade.

Finalmente, no momento da redação deste texto, não é possível afirmar se, durante o processo da avaliação, haverá um equilíbrio ou conciliação entre as duas funções presentes ou se uma delas passará a ter primazia. Esse resultado dependerá do jogo de forças presentes na implantação dos procedimentos operacionais do novo sistema de avaliação.

\section{Referências}

AFONSO, Almerindo Janela. Avaliação educacional: regulação e emancipação: para uma sociologia das políticas avaliativas contemporâneas. São Paulo: Cortez, 2000.

BELLONI, Isaura. A função social da avaliação institucional. In DIAS SOBRINHO, José; RISTOFF. Dilvo (org.) Universidade desconstruída; avaliação institucional e resistência. Florianópolis: Insular, 2000

BRASIL. LEI 10.861, de 14/4/2004. Institui o Sistema Nacional de Avaliação da Educação Superior.

BRASIL. MEC. Portaria no 2.051, de 9/7/2004. Regulamenta os procedimentos de avaliação do Sistema Nacional de Avaliação da Educação Superior.

CABANAS, José Maria. Pedagogia Axiológica: la educación ante los valores. Madrid: Dykinson, 1998.

CEA: Bases para uma nova proposta de avaliação da educação superior. Disponível em: http://portal.mec.gov.br/arquivos/pdf/sinaes.pdf. Acessado em: 08 mar.2004.

CONAES. Diretrizes para a avaliação das instituições de educação superior. Disponível em: http://portal.mec.gov.br/arquivos/pdf/diretrizes.pdf . Acessado em: 14 ago. 2004

DIAS SOBRINHO, José. Avaliação institucional na perspectiva da Integração. In DIAS SOBRINHO, José.; RISTOFF. Dilvo (org.). Universidade desconstruída; avaliação institucional e resistência. Florianópolis: Insular, 2000 
HELENE, Otaviano. O Inep e as avaliações. Disponível em: http:// www.inep.gov.br/imprensa/artigos/inep_avaliacoes.htm . Acessado em: 05 jun. 2003.

PAIUB. Documento básico avaliação das universidades brasileiras. 26 nov. 1993.

ROBBINS, Stephen; COULTER, Mary. Administração. 5. ed. Rio de Janeiro: Prentice-Hall do Brasil, 1998.

SANTOS, Gislene A (Org.). Universidade, formação, cidadania. São Paulo: Cortez, 2001. 